\title{
Influence of sky temperatures on building energy needs
}

\author{
Francesco Asdrubali ${ }^{1}$, Luca Evangelisti ${ }^{1}$, Gianluca Grazieschi ${ }^{2}$, Claudia Guattari ${ }^{1}$ \\ ${ }^{1}$ Roma TRE University, Department of Engineering, Rome, Italy \\ ${ }^{2}$ Niccolò Cusano University, Department of Engineering, Rome, Italy
}

\begin{abstract}
Many studies have been conducted on sky temperature models and sky emissivity. Different correlations have been proposed by researchers, over the years. Sky models are however related to local weather conditions and specific sites. These models do not cover the whole planet even though sky temperature assessment is necessary to evaluate the net radiative heat transfers between surfaces and sky vault. Consequently, taking into account building energy performance, radiative cooling and other engineering purposes, the evaluation of sky temperature is fundamental and needs to be properly accounted.

The aim of this study is to simulate the influence of different correlations, carried out in diverse geographical areas, on building annual energy needs, by implementing them in a dynamic simulation code. In particular, three different climatic conditions (mild temperate, snowy and dry) were considered.
\end{abstract}

\section{Introduction}

When the sunlight heats up the Earth, the adsorbed energy is re-emitted as infrared thermal radiation, which is what we perceive as heat and this is essential to guarantee adequate living conditions (Kuehn et al, 1998).

Thanks to the atmosphere, it is possible to avoid the release towards the sky during the night of the absorbed radiation during the day. Moreover, the atmosphere is plentiful of water vapor, which together with other greenhouse gases, such as methane and carbon and dioxide, allow the Earth to remain warm enough (Liou, 2002), (Chandrasekar, 2010).

Heat exchange between the exterior surface of a building and the environment is based on radiative and convective mechanisms. Since many years, these phenomena were considered and studied by using an effective external air temperature named sol-air temperature (Kuehn et al, 1998). Thermal exchange linked to the sky longwave radiation can be associated to an actual sky temperature and currently building energy models apply equations that can assess the temperature of the sky.

The sky longwave radiation exchange depends on the effective sky temperature. Taking into account buildings behavior, radiative cooling is a result of heat loss by longwave radiation emission towards the sky, assuming the sky as a heat sink for the external surfaces. The radiative cooling is higher during the night when the sky is clear, and humidity is low (Vall and Castell, 2017).
It is well-known that all bodies emit electromagnetic radiation in a wavelength range which is a function of their temperature and at ambient temperature most of the energy is released in the infrared range. Radiative cooling technique aims at generating a cooling net balance between the thermal radiation released from surfaces placed on ground and the atmosphere. Considering buildings, radiative cooling is a passive cooling technique which employs thermal radiation properties for cooling an object or part of a building facing a colder surface, such as the sky (Sellers, 1965). This issue is of great importance: in the European Union, the building sector is responsible of about $40 \%$ of total energy consumption (Directive 2010/31/EU), where air-conditioning of living spaces represents almost half of buildings energy needs. Moreover, such consumptions are growing particularly in emerging countries (Bollino et al, 2017; Toscano et al, 2016).

Several countries, among them Italy, are characterized by an ancient building stock that needs significant retrofit actions (Evangelisti et al, 2016) and today it is possible to employ innovative calculation and simulation tools to estimate heating and cooling energy needs, also thanks to improved relations between the building and the internal and external environment (Nageler, 2018). Among these, the radiative heat transfers between building surfaces and the sky vault are studied and analyzed in this paper. Moreover, to assess the aforementioned heat transfer phenomena, sky emissivity and sky temperature have to be calculated. Typically, sky models are associated to local climatic conditions and precise locations. Currently, several equations are available to estimate the sky temperature, they come from different sites all over the world. It is possible to identify three different approaches: empirical equations, detailed models and the model proposed by the standard ISO 13790 .

In this study, five different sky temperature correlations among the existing ones were compared by simulating a simplified detached building through TRNSYS software. Moreover, the influence of the different equations on annual building energy demands was investigated. All the results obtained by implementing the different sky temperature models in TRNSYS were compared with the sky temperature values provided by the Standard ISO 13790, which suggests simplified formulas when the fictive sky temperature is not available from climatic data. 


\section{Methodology}

It is well-known that TRNSYS (Transient Systems Simulation Program), developed by the University of Wisconsin, is one of the most applied building energy simulation software for the evaluation of heating and cooling energy needs. TRNSYS allows also to calculate the fictive sky temperature, starting from some environmental parameters. By means of the fictive sky temperature, it is possible to assess the long-wave radiation exchange between the exterior surfaces of buildings and the sky vault. Moreover, if among the available weather data, the cloudiness factor (CF) is missing, it can be calculated through the following equation (Skartveit, 1996):

$$
C F=\left(1.4286 \frac{G_{\text {dif }}}{G_{G l o b, H}}-0.3\right)^{0.5}
$$

where $G_{d i f}$ is the diffuse radiation on the horizontal and $G_{G l o b, H}$ is the total radiation on the horizontal. The TRNSYS subroutine (called Type 69) employs the Berdahl and Martin formula (Martin and Berdhal, 1984) to calculate the sky emissivity and thus the sky temperature:

$T_{s k y}=T_{a m b}\left[\varepsilon_{s k y}+0.8\left(1-\varepsilon_{s k y}\right) C F\right]^{0.25}$

It is worthy to notice a factor equal to 0.8 appears in equation (2). The reason of this value (instead of 1) is related to a cloud base temperature significantly lower than the air temperature at screen height. The radiative heat flux to the building surface is calculated through the equation:

$q_{\text {rad }}=\sigma \varepsilon\left(T_{s}^{4}-T_{f s k y}^{4}\right)$

Where $T_{f s k y}$ is the fictive sky temperature calculated, in turn, as:

$T_{\text {fsky }}=\left(1-f_{\text {sky }}\right) T_{a m b}+f_{s k y} T_{\text {sky }}$

Among the existing empirical models able to evaluate the fictive sky temperature, some emissivity based and some direct models, both for clear and cloudy sky conditions were chosen and described. Then, these correlations were implemented in TRNSYS, for estimating their influence on building annual energy demands. A detached building was simulated and the influence of different correlations on heating and cooling energy demands was analyzed. Finally, the obtained results were compared with the sky temperature values obtained by applying the simplified correlations suggested by the standard ISO 13790. In particular, the present study is focused on the analysis of the following correlations chosen among the empirical models. Tables 1 and 3 refer to the direct models, which provide the sky temperature through a direct equation, as a function of the ambient air temperature $\left(\mathrm{T}_{\mathrm{amb}}\right)$ for the clear and cloudy sky conditions, respectively. Tables 2 and 4 list the analyzed equations belonging to the empirical models based on the assessment of the emissivity value, for the clear and cloudy sky conditions, respectively.
More in detail, considering clear sky direct models (Table 1), two correlations were studied: Swinbank model (1963), which can assess the sky temperature knowing only the ambient air temperature parameter $\left(\mathrm{T}_{\mathrm{amb}}\right)$; Garg correlation (1982), assumed the temperature of the sky is $20^{\circ} \mathrm{C}$ below the ambient temperature. Both equations were carried out by means of experimental investigations conducted in Australia.

Table 2 shows the emissivity-based correlations under cloudy sky conditions. Raman (1935) defined his model starting from the first study about this topic conducted in 1918 and properly modifying coefficients. Berdahl and Martin (1984), collected a set of almost 5 years sky longwave radiation data in 6 different cities. Tang et al. (2004) carried out a correlation to calculate sky emissivity, which can be considered effective for a temperature range between $19^{\circ} \mathrm{C}$ and $33.5^{\circ} \mathrm{C}$.

Taking into account cloudy sky conditions, Table 3 lists the investigated direct models. Dreyfus (1962) proposed a very simple equation founded on the identity between sky and ambient temperature values. Whillier model (1967) defined a difference between sky and ambient temperatures equal to $6^{\circ} \mathrm{C}$. Fuentes correlation (1987) introduced a new model employing a clearness index, obtained by studies conducted in 68 U.S. cities.

Regarding the empirical emissivity-based models for cloudy sky conditions (Table 4), the Berdahl and Martin model (1984) is grounded on the cloud sky fraction ( $\left.f_{\text {cloud }}\right)$, which is an index that have different values in function of the sky conditions, equal to 0 for the clear sky, and equal to 1 for overcast sky. In case of opaque clouds conditions, the emissivity value is supposed to be equal to 1 . The Daguenet model (1985) is grounded on vapor pressure value $(\mathrm{Pv})$ and cloudiness degree $(\mathrm{N})$. The $\mathrm{N}$ parameter ranges from 8 , that means clear sky conditions, to 0 for the overcast sky.

\begin{tabular}{|l|l|l|c|}
\hline Table 1. Empirical clear sky direct models. \\
\hline Reference & Date & Correlation & $\begin{array}{c}\text { Measurement } \\
\text { site }\end{array}$ \\
\hline Swinbank & 1963 & $T_{s k y}=0.0552 T_{a m b}^{1.5}$ & Australia \\
\hline Garg & 1982 & $T_{s k y}=T_{a m b}-20$ & Australia \\
\hline
\end{tabular}

Table 2. Empirical clear sky models based on emissivity correlations.

\begin{tabular}{|c|c|c|c|}
\hline Author & Date & Emissivity & $\begin{array}{c}\text { Measurement } \\
\text { site } \\
\end{array}$ \\
\hline Raman & 1935 & $\varepsilon_{s k y}=0.62+0.029 P_{v}^{0.5}$ & India \\
\hline $\begin{array}{l}\text { Berdahl } \\
\text { and Martin }\end{array}$ & 1984 & $\begin{array}{l}\varepsilon_{\text {sky }} \\
=0.711+0.56\left(T_{d p} / 100\right) \\
+0.73\left(T_{d p} / 100\right)^{2}\end{array}$ & $\begin{array}{l}\text { Arizona, } \\
\text { Texas, } \\
\text { Maryland, } \\
\text { Missouri, } \\
\text { Florida and } \\
\text { Nevada }\end{array}$ \\
\hline Tang et al. & 2004 & $\varepsilon_{s k y}=0.754+0.0044 T_{d p}$ & Israel \\
\hline
\end{tabular}

\begin{tabular}{|l|c|l|c|}
\multicolumn{4}{|c}{ Table 3. Empirical cloudy sky direct models. } \\
\hline Reference & Date & Correlation & $\begin{array}{c}\text { Measurement } \\
\text { site }\end{array}$ \\
\hline Dreyfus & 1960 & $T_{s k y}=T_{a m b}$ & - \\
\hline Whillier & 1967 & $T_{s k y}=T_{a m b}-6$ & United States \\
\hline
\end{tabular}




\begin{tabular}{|l|l|l|c|}
\hline Fuentes & 1987 & $\begin{array}{l}T_{\text {sky }} \\
=0.037536 T_{a m b}^{1.5} \\
+0.32 T_{a m b}\end{array}$ & $\begin{array}{c}68 \text { cities in } \\
\text { U.S.A. }\end{array}$ \\
\hline
\end{tabular}

Table 4. Empirical cloudy sky atmospheric emissivity models.

\begin{tabular}{|l|l|l|l|}
\hline Reference & Date & Emissivity & $\begin{array}{l}\text { Measurement } \\
\text { site }\end{array}$ \\
\hline \multirow{3}{*}{$\begin{array}{l}\text { Berdahl } \\
\text { and } \\
\text { Martin }\end{array}$} & \multirow{2}{*}{1984} & $\begin{array}{l}\varepsilon_{\text {sky }} \\
=\varepsilon_{\text {clear }-k y} \\
+\varepsilon_{\text {cloud }}(1 \\
\left.-\varepsilon_{\text {clear }-k y}\right) f_{\text {cloud }}\end{array}$ & $\begin{array}{l}\text { Arizona, } \\
\text { Texas, }\end{array}$ \\
\hline Daguenet & 1985 & $\begin{array}{l}\text { Maryland, } \\
\text { Missouri, } \\
\text { Florida and } \\
\text { Nevada }\end{array}$ \\
\hline & $\begin{array}{l}\varepsilon_{\text {sky }} \\
=\left(0.53+0.065 P_{v}^{0.5}\right)(1 \\
-0.1 N)+0.1 N\end{array}$ & England \\
\hline
\end{tabular}

When data for the sky temperature calculation are not available, considering the heat transfers phenomena that occur between buildings and the sky vault, the Standard ISO 13790 makes possible to calculate the fictive sky temperature through the equations listed in Table 5. Through the simplified methodology given by the Standard, it is possible to assess the annual energy requirement in terms of energy needs.

Table 5. Direct models according to ISO 13790.
\begin{tabular}{|l|l|}
\hline Correlation & Site \\
\hline$T_{\text {sky }}=T_{a m b}-11$ & Temperate areas \\
\hline$T_{\text {sky }}=T_{a m b}-9$ & Sub-polar areas \\
\hline$T_{\text {sky }}=T_{a m b}-13$ & Tropical areas \\
\hline
\end{tabular}

Taking into account the precise location of the building, it is possible to define the climatic area and the suitable correlation to calculate the fictive sky temperature. According to Köppen classification (Köppen, 1900), which is a common classification of the world climate conditions, different climatic areas can be recognized. On the other hand, the Standard ISO 13790 provides an organization of the different climatic area over the world based on the latitudes. The Standard classification leads to the identification of three areas: sub-polar, temperate and tropical. However, it is worthy to notice that the most diffuse classification of the worldwide climatic conditions is the Köppen one, which is grounded on the local temperature and precipitation data, over a proper observation period.

The analysis of this study was focused on quantifying the differences in terms of heating and cooling energy demands employing different correlations and the ISO 13790 one. Since no correlations were developed for the Mediterranean area, to achieve this goal, a building locating in this geographical area was simulated by means of different correlations developed by experimental investigations conducted in other parts of the world. The analyzed sky temperature correlations were compared, also investigating the influence of these different equations on annual building energy demands, by means of TRNSYS software. All the results were compared with the sky temperature values obtained by applying the standard ISO 13790, which suggests simplified formulas when the sky temperature is not available from climatic data.

\section{Results and Discussion}

The first step of the study was the analysis of the empirical correlations to estimate and compare the sky temperatures values, using the Typical Meteorological Years (TMY) available for specific cities. In particular, three locations characterized by different climatic conditions, mild temperate, snowy and dry conditions, according to Köppen world climate classification - were chosen. Starting from this, three representative cities were selected (Rome, Vienna and Tripoli) and different correlations were applied, considering clear and cloudy sky conditions. Considering clear sky conditions, the correlations listed in Tables 1 and 2 were tested; taking into account cloudy sky conditions, equations described in Tables 3 and 4 were applied. Each analysis was performed starting from two significant days, in January and July. Mild temperate conditions were studied by implementing in the simulation code the weather-data of Rome. Regarding the clear sky conditions in January (Fig. 1a), it is possible to notice that the temperature values provided by the Standard ISO 13790 are significantly higher compared to the ones calculated by means of the analyzed correlations.

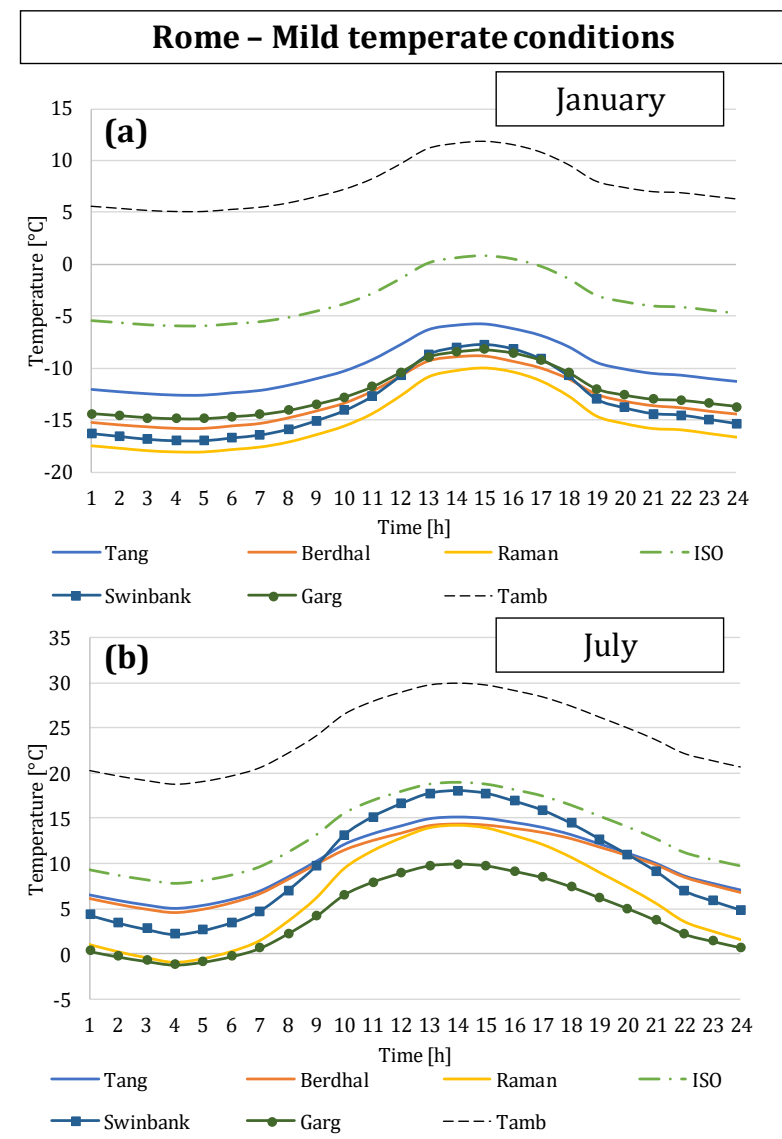



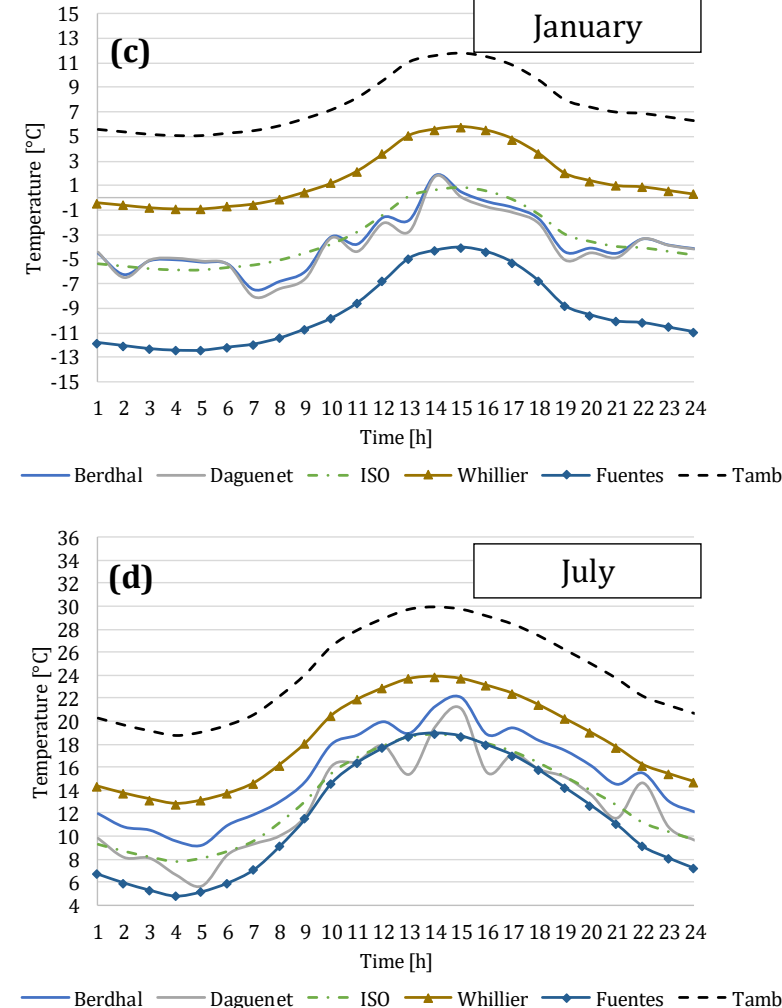

Fig 1. Comparison among the temperatures calculated using different models in Rome, during January and July for clear $(a),(b)$ and cloudy sky conditions $(c),(d)$.

These differences range between about $6^{\circ} \mathrm{C}$, applying Tang model, to about $12^{\circ} \mathrm{C}$ if Raman equation is employed. Taking into account the summer season (July) (Fig. 1b), lower differences were obtained, from a minimum value of about $1.5^{\circ} \mathrm{C}$ for Swinbank correlation to a maximum one of about $10{ }^{\circ} \mathrm{C}$. Considering Figs. 1c and 1d, representing the cloudy sky conditions in January and July respectively, a similar trend can be observed. The ISO 13790 values represent average values among the ones provided by the other correlations, this is particularly evident in winter conditions. In fact, the emissivity-based model Berdhal and Deguenet provided similar values compared to the Standar; the analysed direct models, Fuentes, Whillier and Dreyfus (represented through Tamb value) provided lower values of about $8^{\circ} \mathrm{C}$ (Fuentes) and higher values from $5^{\circ} \mathrm{C}$ to $10^{\circ} \mathrm{C}$ (Whillier and Dreyfus, respectively.

When analyzing the snowy climatic conditions in Vienna under clear sky, both for January and July (see Fig. 2a and $2 b$ ), it is possible to observe that the values provided by the Standard have the same trend shown in the previous case. In fact, the ISO values are higher than the ones provided by the analyzed correlations, in January the difference ranges between about $10^{\circ} \mathrm{C}$ (Garg equation) and about $15^{\circ} \mathrm{C}$ for the other correlations. In July a narrower range of differences was found, between $3^{\circ} \mathrm{C}$ and $5^{\circ} \mathrm{C}$. In this case the lower difference is obtained applying the Tang correlations and the higher one using the Garg model. For the cloudy sky conditions, the ISO 13790 gave lower values except for the Fuentes equations that provided the lowest results, both in January (about $8^{\circ} \mathrm{C}$ ) and in July (about $4^{\circ} \mathrm{C}$ ).

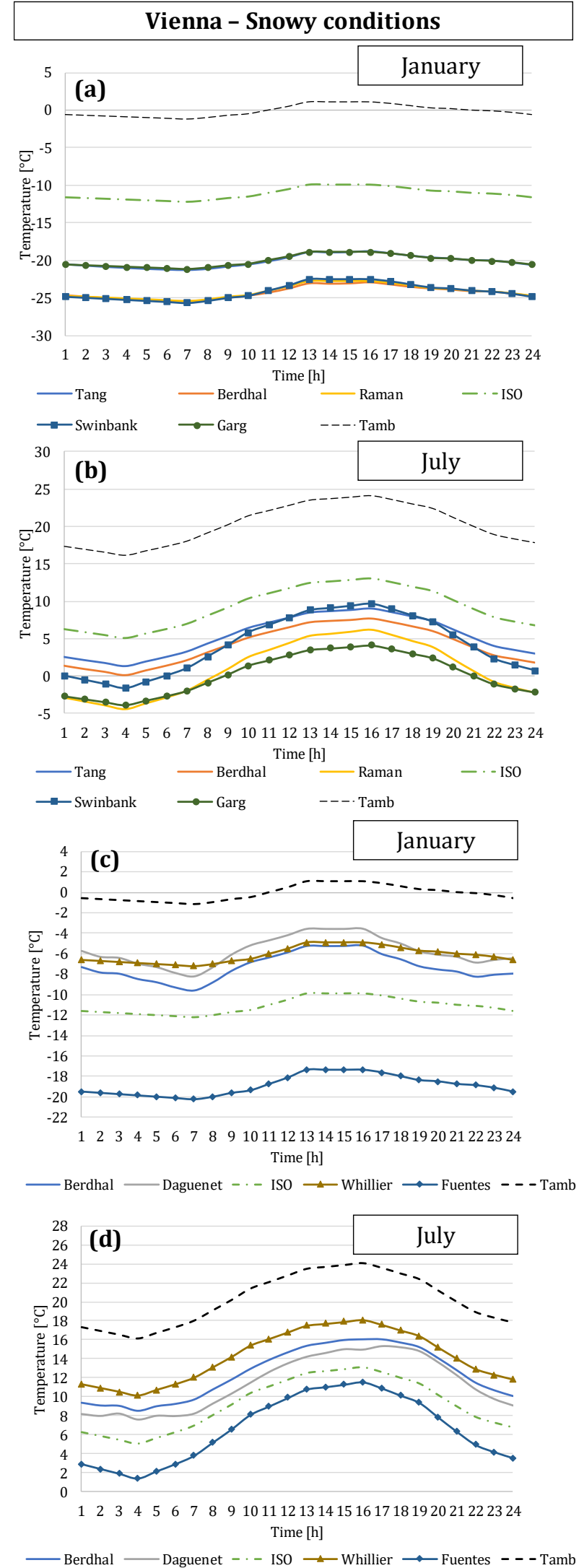

Fig 2. Comparison among the temperatures calculated using different models in Vienna, during January and July for clear (a),(b) and cloudy sky conditions $(c),(d)$. 

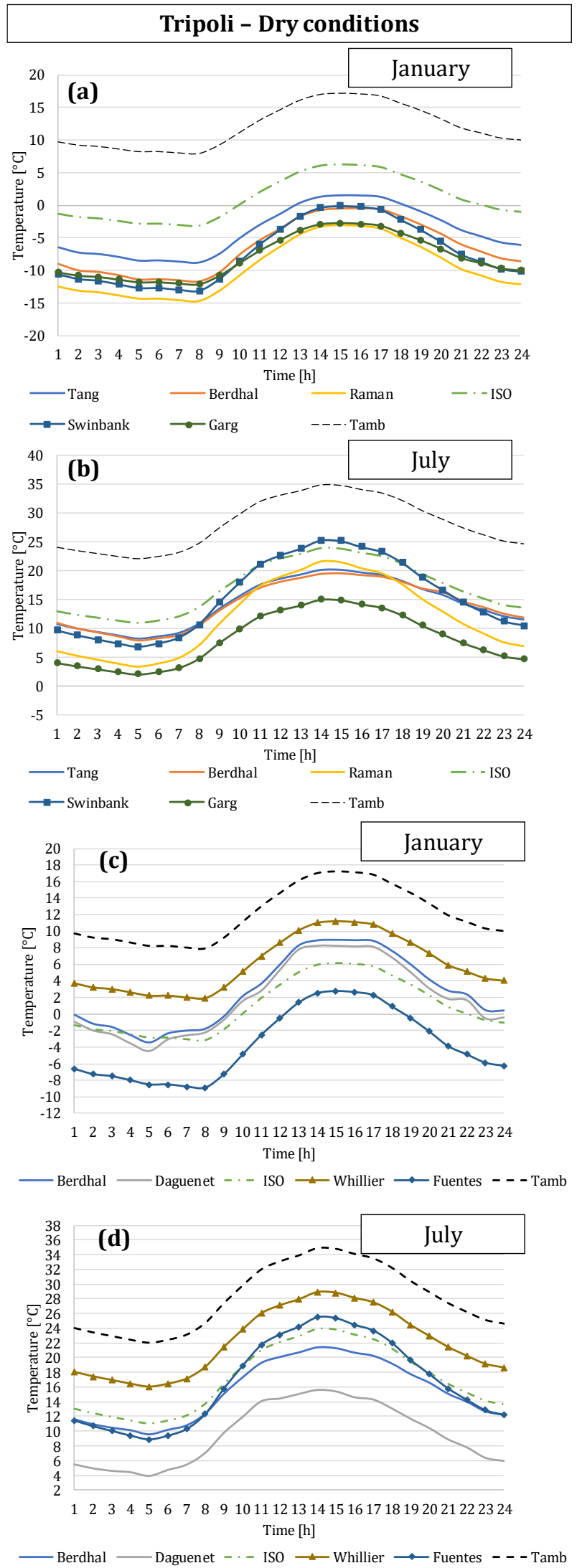

Fig .3 Comparison among the temperatures calculated using different models in Tripoli, during January and July for clear $(a),(b)$ and cloudy sky conditions $(c),(d)$.
Also taking into account the dry conditions registered in Tripoli (Fig. 3), the Standard is not in agreement with the analyzed models, except for July when Swinbank and Fuentes correlations are considered, both under clear and cloudy sky conditions.

More in general, it is possible to affirm that the values provided by the Standard and the correlations carried out for different geographical areas are quite different among each other. Then, it could be difficult to choose which correlation is more suitable to be employed in a dynamic simulation to calculate the heating and cooling energy demands.

Usually the fictive sky temperature $\left(\mathrm{T}_{\text {fsky }}\right)$ is needed in order to take into account the long wave radiation transferred to the external surface; the $\mathrm{T}_{\text {fsky }}$ is an input in the simulated model together with the sky view factor $(F)$. For vertical walls and isolated buildings, a realistic value for $\mathrm{F}$ is 0.5 , for horizontal surfaces $\mathrm{F}$ is equal to 1 .

Starting from this simulation setup, the energy demands for heating and cooling were simulated, and the obtained results are shown in Fig. 4. Here, five significant equations to calculate the sky temperature were implemented in the dynamic model (two sky emissivity based and three direct correlations), then the obtained results were analyzed and compared with the simplified formula suggested by ISO 13790. It is known that during the year clear and cloudy conditions sky alternate with each other and under cloudy conditions the infrared radiation is higher. Consequently, the clear sky models need to be reviewed in terms of cloudy sky conditions. But it is worthy to notice that the cloudiness effect is quite difficult to be evaluated, just few studies provided correlations that can be employed under cloudy sky conditions. By implementing these equations in the TRNSYS model, the annual heating and cooling energy demands were calculated and compared among the three different climatic conditions for each correlation.

Regarding this, an isolated building was simulated considering a very diffused construction technique for the most recent buildings. The walls stratigraphy is composed by plaster $(0.020 \mathrm{~m})$, concrete $(0.220 \mathrm{~m})$, xps $(0.040 \mathrm{~m})$ and plaster again $(0.020 \mathrm{~m})$, the total walls thickness I equal to $0.300 \mathrm{~m}$ and it is characterized by a thermal transmittance of $0.587 \mathrm{~W} / \mathrm{m}^{2} \mathrm{~K}$.

The windows cover an area of $18 \mathrm{~m}^{2}$ (width $0.77 \mathrm{~m}$ and height $1.08 \mathrm{~m}$ ) with a $\mathrm{u}$-value equal to $5.61 \mathrm{~W} / \mathrm{m}^{2} \mathrm{~K}$. The envelope is characterized by a solar absorptance coefficient equal to 0.6 and the infiltration rate was set equal to 0.5 $1 / \mathrm{h}$. Regarding the indoor set-point temperature, it was set equal to $26^{\circ} \mathrm{C}$ for cooling and $20^{\circ} \mathrm{C}$ for heating.

Fig. 4 shows the simulation results for each correlation employed for each considered climatic conditions, typical for the Mediterranean area. 

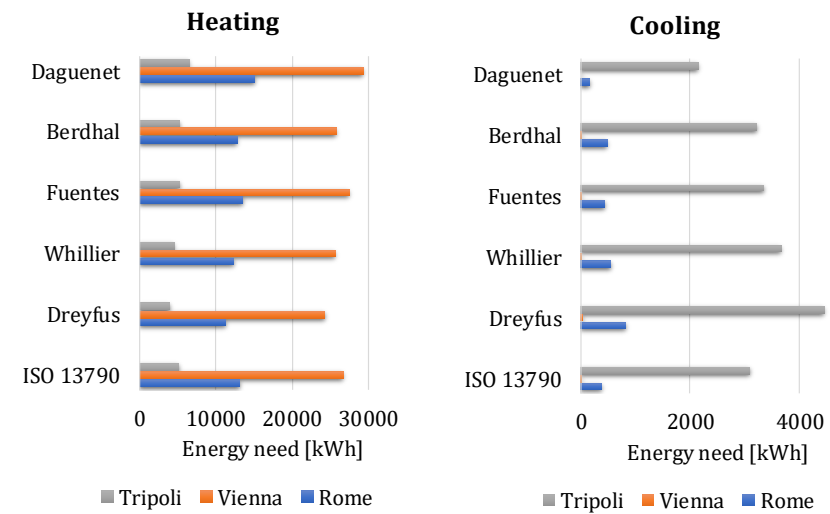

Fig 4. Comparison among the annual building energy needs for heating (Qheat) and cooling (Qcool), using different correlations.

Considering mild temperate conditions in Rome, both heating and cooling energy demands must be simulated. Analyzing heating energy needs, the highest differences with the results given by the ISO approach can be obtained through the Daguenet equation $(+14 \%)$. The lowest percentage differences can be achieved using the Dreyfus formula $(-15 \%)$. By applying other correlations intermediate results can be found, the percentage differences range from $-6 \%$ to $+3 \%$. In terms of cooling energy needs, the highest differences can be observed by applying Dreyfus formula $(+113 \%)$ and Whillier correlation $(+45 \%)$. On the other hand, the lowest percentage difference can be reached using the Daguenet equation $(-57 \%)$. The other correlations provided percentage differences of about $12 \%$ (Fuentes) and $24 \%$ (Berdhal).

For the climatic conditions in Vienna (snowy conditions) the highest heating energy needs among the studied conditions and a negligible demand for cooling. Regarding the heating energy needs, the same trend of the previous case was achieved: the highest difference was obtained by employing the Daguenet formula (10\%) and the lowest one by using the Dreyfus equation (-9\%). The other correlations led to percentage differences that range between $-4 \%$ and $+2 \%$. Analyzing cooling energy needs, the percentage difference values are much higher than the other climatic conditions but, as mentioned before, they refer to almost negligible cooling energy demands.

In the dry conditions case, the tendency highlighted in the previous case studies was confirmed once again. In fact, the highest differences can be obtained by using the Daguenet formula $(+26 \%)$. The Dreyfus correlation allows to obtain the lowest energy need $(-25 \%)$. The other correlations allow to achieve different conditions, with percentage differences ranging from $-11 \%$ to $+4 \%$.

\section{Conclusion}

Among all the various correlations, no specific equations are currently available for the Mediterranean area and the proposal of a specific sky temperature formula can be useful for engineering purposes, in particular when detailed simulations are needed, such as in case studies related to nearly zero energy buildings. Carrying out simulation models applying different sky temperatures models can lead to different results in terms of annual heating and cooling energy demands. Comparing the results obtained by applying the most diffused sky temperature correlations, several deviations were found. The lack of a specific equation for the Mediterranean area does not allow to define the best existing correlation to be applied by users in building energy simulations and engineering applications. Implementing in a dynamic simulation software the simplified equation provided by ISO 13790 or a specific sky temperature model can lead to significant temperature differences, both under clear and cloudy sky conditions happen. Furthermore, taking into account the effects of employing different correlations in building energy simulations, it was found that heating and cooling energy needs can be affected by considerable percentage differences, ranging from $-57 \%$ to $+45 \%$ for the climatic conditions registered in Rome. Considering the snowy conditions proper of Vienna's weather, the percentage difference in terms of heating demands are quite low, between $-9 \%$ and $3 \%$. The results are completely opposite if the cooling needs are considered. Finally, regarding the dry climatic conditions (Tripoli), percentage differences ranging from $-30 \%$ to $44 \%$ were found.

The direct follow up of this study is to provide a new specific correlation obtained using experimental longwave radiation data measured in Rome (Italy) by employing a pyrgeometer. This experimental measurement campaign is still ongoing.

\section{Acknowledgment}

This research has been carried out in association with the "Renovation of existing buildings in NZEB vision (nearly Zero Energy Buildings)" Project of National Interest (Progetto di Ricerca di Interesse Nazionale - PRIN) funded by the Italian Ministry of Education, Universities and Research (MIUR).

\section{References}

Berdahl, P, Martin M. Emissivity of clear skies. Sol Energy 1984;32(5):663-64.

Bollino, C.A. Asdrubali, F. Polinori, P. Bigerna, S. Micheli, S. Guattari, C. Rotili, A. (2017). A note on medium- and long-term global energy prospects and scenarios. Sustainability 9, 833.

Chandrasekar A. (2010). Basics of atmospheric science, Publisher: PHI Learning ISBN-10: 8120340221.

Daguenet, M. (1985). Les séchoirs solaires: théorie et pratique. Paris: United Nations Educational, Scientific and Cultural Organization.

Dreyfus M.G. and Hilleary, D. T. (1962).Aerospace Engng $21,42$.

European Parliament. Directive 2010/31/EU of the European Parliament and of the Council of 19 May 2010 on the energy performance of buildings. J Eur Union 153 (2010) 13-35.

Evangelisti, L. Guattari, C. Gori, P. (2015). Energy Retrofit Strategies for Residential Building Envelopes: An 
Italian Case Study of an Early-50s Building, Sustainability 7 10445-10460.

Fuentes, M.K., 1987. A simplified thermal model for flat plate photovoltaic arrays. Report SAND85-0330. Albuquerque: Sandia National Labs.

International Organization for Standardization (2008). Energy performance of buildings - Calculation of energy use for space heating and cooling (ISO 13790).

Köppen climate classification. Avilable on-line: http://hanschen.org/koppen/\#data (Accessed on 13th June 2018).

Kuehn, T.H. Ramsey, J.W. Threlkeld, J.L. (1998).Thermal environmental engineering. 3rd ed. Hoboken, NJ: Prentice Hall,

Garg, H.P. 1982. Treatise on solar Energy: Fundamental of solar energy. Chichester: JohnWiley \& Sons.

Liou K.N. An Introduction to Atmospheric Radiation, Editor: Academic Press; 2nd edition (2002), ISBN-10: 0124514510 .

Martin, M. Berdahl, P. (1984). Characteristics of Infrared Sky Radiation in the United States, Lawrence Berkeley Laboratory, University of California - Berkeley, Sol Energy Vol. 33, No. 3/4, pp. 321-336.

Nageler, P. Schweiger, G. Pichler, M. Brandl, D. Macha, T. Heimratha, R. Schranzhofer, H. Hochenauer, C. (2018). Validation of dynamic building energy simulation tools based on a real test-box with thermally activated building systems (TABS). Energ Buildings. 168:42-55.
Raman, PK. Heat radiation from the atmosphere at night. (1935). Proceedings of Indian Academy of Sciences; $1: 815$.

Sellers. W.D. (1965). Physical climatology. Chicago London: University of Chicago.

Skartveit, A. Olseth, J.A. Czeplack, G. Rommel, M. (1996). On the estimation of atmospheric radiation from surface meteorological data, Solar Energy 56(4) 349-359.

Swinbank, W. (1963). Long-wave radiation from clear skies. Quarterly Journal of Royal Meteorological Society 89:339-48.

Tang, R.Y. Etzion, I.A. Meir. (2004). Estimates of clear night sky emissivity in the Negev Highlands, Israel. Energ Convers Manage 45(11):1831-1843.

Toscano, A. Bilotti, F. Asdrubali, F. Guattari, C. Evangelisti, L. Basilicata, C. (2016). Recent trends in the world gas market: Economical, geopolitical and environmental aspects. Sustainability 8, 154.

TRNSYS, Transient system simulation tool, Available online: http://www.trnsys.com/ (Accessed on 13th June 2018).

Vall, S. and Castell, A. (2017). Radiative cooling as lowgrade energy source: A literature review. Renew Sustain Energy Rev 77 803-820.

Whillier, A. (1967). Design factors influencing solar collectors in low temperature engineering applications of solar energy. NewYork, ASHRAE. 